\title{
MAINTENANCE AND REPAIR SCHEME FOR CORRODED STIFFENED STEEL BOX GIRDER BRIDGES BASED ON ULTIMATE STRENGTH RELIABILITY AND RISK ASSESSMENTS
}

\author{
Yasser SHARIFI ${ }^{\mathrm{a}}$, Jeom Kee PAIK ${ }^{\mathrm{b}}$ \\ ${ }^{a}$ Department of Civil Engineering, Vali-e-Asr University of Rafsanjan, \\ 22 Bahman Square, Rafsanjan, Iran \\ ${ }^{a, b}$ The Korea Ship and Offshore Research Institute (The Lloyd's Register Foundation \\ Research Centre of Excellence) at Pusan National University, Busandaehak-ro 63 beon-gil, \\ Gumjeong-Gu, Busan 609-735, Republic of Korea
}

Received 18 September 2014; accepted 22 September 2014

\begin{abstract}
The aims of this study are to investigate the effect of corrosion on the load-carrying capacity of stiffened steel box girder bridges and to formulate a repair schedule using reliability-based approaches for such bridges as they age. A credible scenario for a corroded steel box section is estimated. Corrosion rates and their probabilistic characterization are calculated based on the available data. A probabilistic model of ultimate box girder strength is established based on an analytical formula that considers corrosion-related time-dependent strength degradation. The results generated with this model may be useful in the development of an optimized and accurate maintenance and repair schedule for existing steel box girder bridges.
\end{abstract}

Keywords: steel box girder-bridge, ultimate strength, corrosion, stiffeners, probabilistic model, maintenance and repair.

\section{Introduction}

Bridges are an important type of infrastructure. Optimal decisions about bridge maintenance and rehabilitation have tremendous economic and safety implications and depend heavily on the results of evaluations of residual safety and carrying capacity. The evaluation of existing bridges has become an increasingly important topic in the effort to deal with deteriorating infrastructure. As of 2004, in the United States alone $26.6 \%$ of the nation's bridges (158319) were classified as structurally deficient or functionally obsolete. It is estimated that about $\$ 10$ billion per year for 20 years will be needed to eliminate all bridge deficiencies, not to mention the additional expenditure required to maintain these bridges at their existing level (Czarnecki, Nowak 2008; Sharifi, Paik 2010, 2011; Sharifi 2011; Sharifi, Tohidi 2014a, 2014b; Tohidi, Sharifi 2014), and the situation in other countries is similar. To avoid the high costs of replacement, bridge evaluation must accurately reveal the current load-carrying capacity of the structure and predict loads and further changes in the capacity (deterioration) for an appropriate interval of time. Despite remarkable advances in modeling, in numerical or analytical techniques for response and behavior analysis, and in the assessment of the ultimate strength or stability analysis of bridges (Gordo, Guedes Soares 2009; Saad-Eldeeen et al. 2013), it is extremely difficult to realistically evaluate the residual safety or carrying capacity, especially when bridges are deteriorated or damaged to a significant degree (Nowak 2004). Steel box girder bridges are an important and widely used bridge type. This type of bridge involves plate mem-

Corresponding author:

Y. Sharifi E-mai: yasser_sharifi@yahoo.com 
bers, which as thin-walled structures are highly prone to corrosion damage. There is thus a need for efficient steel box girder bridge evaluation procedures. The main parameters that determine the structural performance of steel box girder bridges are random variables, but new advances that are significant for bridge evaluation have taken place in the area of probabilistic methods. Reliability has become an issue of particular importance for bridges carrying highway traffic. More exact methods of analysis that leave less generous safety margins over and above the minimum required by specifications, combined with a more deleterious service environment and limitations on maintenance, reduce the reliability of bridges. A probabilistic treatment is appropriate to account for the influence of these trends (Nowak, Zhou 1990).

Load effect and resistance of a bridge are random variables. Therefore, it is common to measure bridge structural performance in terms of reliability and probability. The reliability methods allow for consideration of uncertainties associated with material properties, geometry and dimensions, loads and environmental conditions (Melchers, Jeffrey 2008; Melchers 2005; Kayser, Nowak 1989; Reid 2009; Gayton, Lemaire 2009; Lazakis et al. 2010; Ivanov 2013; Payer, Schellin 2013).

System models are generally employed for the reliability analysis of the strength failure of bridges. However, because the rehabilitation or repair of bending or shear failure is usually made necessary by local limit state failure, rather than structural collapse, element-level reliability analysis may be more suitable than system-level reliability analysis to determine the ultimate strength of bridges. As flexural failure is one of the most common failure modes in steel girder bridges, this paper considers the ultimate moment resistance. An example is presented to demonstrate the application of the proposed method for the repair and maintenance schedule of steel box girder bridges, as it is recognized that a corroded steel box girder cannot be guaranteed safe when reliability approaches are used.

\section{Notation}

The following symbols are used in this paper:

$A$ - corrosion parameter or cross-sectional area;

$B$ - corrosion parameter or width of box section;

$C$ - average corrosion penetration; $t$ - time in years and plate thickness of a member;

$A_{B}, A^{\prime}{ }_{B}, A_{D}$ - sectional area of the outer bottom, inner or upper (deck);

$A_{S}$ - half of the sectional area of the side structure, including any longitudinal bulkhead;

$D$ - box depth;

$D_{B}$ - height of the double bottom;

$b$ - breadth of the plate between the longitudinal stiffeners;

$\sigma_{u}$ - ultimate compressive strength of the plate;

$\sigma_{u D}, \sigma_{u S}$ - ultimate compressive strength of a representative plate at the upper or side shell;

$\sigma_{y}$ - mean yield strength of the material;

$\sigma_{y B}, \sigma_{y S}$ - mean yield strength of the bottom or side shell;

$H$ - depth of the box section in the linear elastic state;

$M_{u}, M_{u o}$ - random variables representing the ultimate strength of a corroded or noncorroded box girder;

$g$ - height of the neutral axis (equations (2) or (3));

$\beta$ - slenderness ratio of the plating between the longitudinal stiffeners;

$S M$ - elastic section modulus of the bottom plate;

$g^{\prime}$ - elastic horizontal neutral axis (equations (5) or (6));

$\lambda$ - bias factor, which is the ratio of the mean to the nominal value or slenderness ratio of a stiffener with fully effective plating;

$V$ - coefficient of variation;

$M_{D}$ - dead-load moment;

$M_{L}$ - live-load moment;

$I M$ - dynamic live load;

$g(x)$ - ultimate limit state function;

$\sigma_{x i}-$ standard deviation of the random variable $x_{i}$;

$\gamma$ - reliability index;

$\mu_{x}$ - mean value of the random variable $x_{i}$;

$E$ - Young's modulus;

$T$ - ifetime of the bridge.

\section{Corrosion-damaged model scenario}

There are several forms of corrosion. The most important parameters to be addressed are the rate and progress of corrosion (Melchers 2005; Melchers, Jeffrey 
2008; Paik, Melchers 2008). It is agreed that the corrosion of steel is affected by several factors, including the type of steel, surface protection, environmental effects, and presence of pollutants, crevices, and stress. The effects of corrosion can vary from nonstructural maintenance problems to local failure and even overall collapse. Four major categories of corrosion effects have been identified: loss of material, creation of stress concentration, introduction of unintended fixity, and introduction of unintended movement. The most common is loss of material. This can be either uniform, when corrosion affects large areas of a bridge component, or localized, where it takes the form of pits (Czarnecki, Nowak 2008; Paik, Melchers 2008). The uniform corrosion effect is the most important type of corrosion to affect steel box girder bridges. In this study, a credible model for a corroded cross section of a steel box girder bridge is developed. It has been observed from real deteriorated box girder bridges that the inside of the box cross-section is often corroded in addition to the outside. This trend must thus be taken into account in the development of a corrosiondamaged model. As can be seen in Figure 1, corrosion decreases the thickness of the members (surface stiffeners) of a steel box girder uniformly outside and inside. As the environmental conditions of the outside and inside of the steel box are different, it is assumed that the inside corrosion rate is half that of the outside. The thickness loss $t$ of the inside plate members of the box is thus also half that of the outside loss. This assumption is reliable, as the inside of the steel box is better protected from severe corrosion attack, which is caused by the outside environment.

A probabilistic corrosion rate modeling to estimate the loss of plate thickness is considered here. The model includes time as a basic parameter and other random variables that describe the effects of environment on the rate of corrosion. Data on the corrosion performance of actual steel bridges have been collected

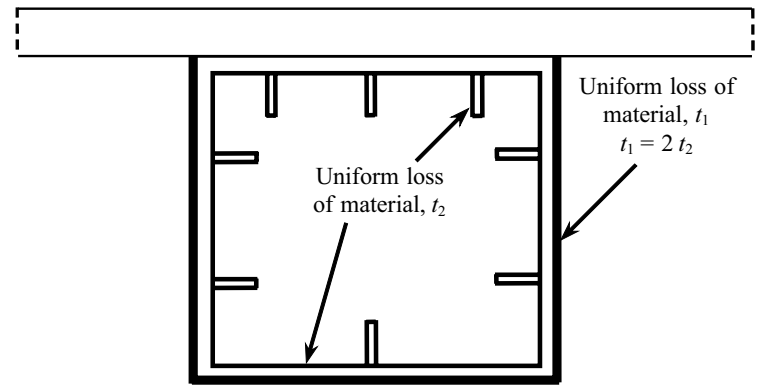

Fig. 1. Proposed model of corroded stiffened steel box girder (cross-section) by Kayser (1988). Other research has shown that corrosion propagation can be modeled with a good degree of accuracy with the following exponential function (Paik et al. 1998; Komp 1987).

$$
C(t)=A t^{B}
$$

where $C(t)$ is the average corrosion penetration in micrometers $\left(10^{-3} \mathrm{~mm}\right), t$ is the time in years, and $A$ and $B$ are parameters to be determined from regression analysis of the experimental data.

Table 1 gives the mean values, coefficients of variation, and coefficients of correlation for $A$ and $B$. The corrosion penetration versus time is plotted in Figure 2. Note that the determination of $A$ and $B$

Table 1. Statistical parameters for $A$ and $B$ (Kayser 1988)

\begin{tabular}{|c|c|c|c|c|}
\hline \multirow[b]{2}{*}{ Parameters } & \multicolumn{2}{|c|}{ Carbon Steel } & \multicolumn{2}{|c|}{ Weathering Steel } \\
\hline & $\begin{array}{c}A \\
\left(\times 10^{-3} \mathrm{~mm}\right)\end{array}$ & B & $\begin{array}{c}A \\
\left(\times 10^{-3} \mathrm{~mm}\right)\end{array}$ & B \\
\hline \multicolumn{5}{|c|}{ Rural Environment } \\
\hline Mean value, $\mu$ & 34.0 & 0.65 & 33.3 & 0.498 \\
\hline $\begin{array}{l}\text { Coefficient of } \\
\text { variation, } \sigma / \mu\end{array}$ & 0.09 & 0.10 & 0.34 & 0.09 \\
\hline $\begin{array}{l}\text { Coefficient of } \\
\text { correlation, }{ }_{\rho} A B\end{array}$ & \multicolumn{2}{|c|}{ Not available } & \multicolumn{2}{|l|}{-0.05} \\
\hline \multicolumn{5}{|c|}{ Urban Environment } \\
\hline Mean value, $\mu$ & 80.2 & 0.593 & 50.7 & 0.567 \\
\hline $\begin{array}{l}\text { Coefficient of } \\
\text { variation, } \sigma / \mu\end{array}$ & 0.42 & 0.40 & 0.30 & 0.37 \\
\hline $\begin{array}{l}\text { Coefficient of } \\
\text { correlation, } \rho_{A B}\end{array}$ & \multicolumn{2}{|l|}{0.68} & \multicolumn{2}{|l|}{0.19} \\
\hline \multicolumn{5}{|c|}{ Marine Environment } \\
\hline Mean value, $\mu$ & 70.6 & 0.789 & 40.2 & 0.557 \\
\hline $\begin{array}{l}\text { Coefficient of } \\
\text { variation, } \sigma / \mu\end{array}$ & 0.66 & 0.49 & 0.22 & 0.10 \\
\hline $\begin{array}{l}\text { Coefficient of } \\
\text { correlation, } \rho_{A B}\end{array}$ & \multicolumn{2}{|l|}{-0.31} & \multicolumn{2}{|l|}{-0.45} \\
\hline
\end{tabular}

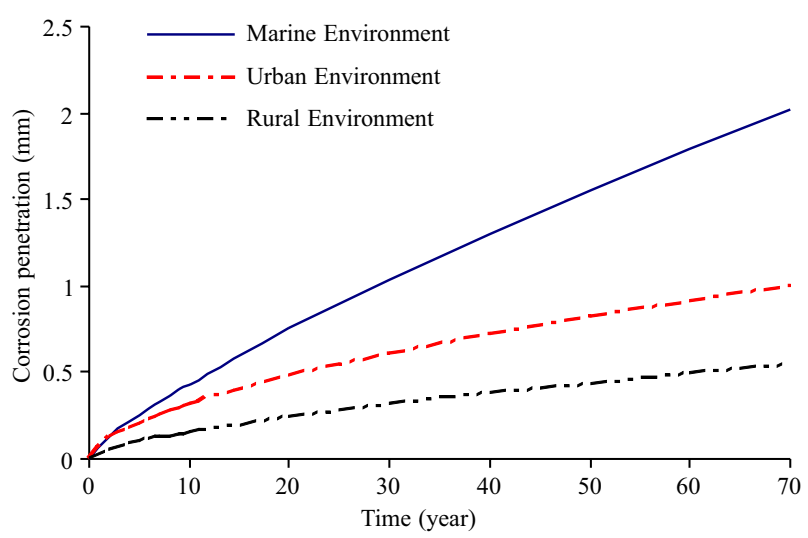

Fig. 2. Corrosion penetration versus time for carbon steel in various environments (Kayser 1988) 
involves a considerable degree of uncertainty. Table 1 shows the rate probabilistic parameters for two types of steel. As carbon steel is commonly found in existing bridges and the marine environment is critical, the carbon steel parameters in a marine environment are applied in this study.

\section{Resistance model}

This study is concerned with the ultimate carrying capacity of existing steel box girder bridges, and thus the ultimate limit state functions must be considered in the modeling. Analytical formulae can be used as an appropriate resistance model to predict the ultimate strength of box girders. The analytical formula suggested by Paik and Mansour (1995) is employed to estimate the ultimate bending moment of a steel box girder, while some modifications of the original PaikMansour method were recently developed (Paik et al. 2013).

Paik and Mansour (1995) assumed a credible distribution of the longitudinal stresses in the hull section in the overall collapse state. They then estimated the stress distribution based on the results of a series of nonlinear finite element calculations for the ultimate limit state, as shown in Figure 3. Based on this distribution, they then derived an explicit analytical formula for the corresponding resistive moment. The accuracy of the formula was then verified by comparison with both experimental and numerical results. The resulting expressions for the ultimate bending strength of a double-bottomed hull are given as follows.

$$
\begin{aligned}
M_{u}=- & A_{D} \sigma_{u D}(D-g)-\frac{A_{S}}{D}(D-H)(D+H-2 g) \sigma_{u S}- \\
& A_{B} g \sigma_{y B}+\frac{A_{B}^{\prime}}{H}\left(g-D_{B}\right)\left[D_{B} \sigma_{u S}-\left(H-D_{B}\right) \sigma_{y S}\right]- \\
& \frac{A_{S} H}{3 D}\left[(2 H-3 g) \sigma_{u S}-(H-3 g) \sigma_{y S}\right],
\end{aligned}
$$

where

$$
\begin{aligned}
H= & \frac{1}{2}\left\{\left(\frac{A_{D} \sigma_{u D}+2 A_{S} \sigma_{u S}-A_{B} \sigma_{y B}-A_{B}^{\prime} \sigma_{y s}}{A_{S}\left(\sigma_{u S}+\sigma_{y s}\right)}\right) D+\right. \\
& {\left[\left(\frac{A_{D} \sigma_{u D}+2 A_{S} \sigma_{u S}-A_{B} \sigma_{y B}-A_{B}^{\prime} \sigma_{y s}}{A_{S}\left(\sigma_{u S}+\sigma_{y s}\right)}\right)^{2} D^{2}+\right.} \\
& \left.\left.\frac{4 A_{B}^{\prime} D_{B}}{A_{S}} D\right]^{1 / 2}\right\} ;
\end{aligned}
$$

$$
g=\frac{\sigma_{y s}}{\sigma_{u s}+\sigma_{y s}} H .
$$

For a single box girder, the formula can be simplified to

$$
\begin{array}{r}
M_{u}=-A_{D} \sigma_{u D}(D-g)-\frac{A_{S}}{D}(D-H)(D+H-2 g) \sigma_{u S}- \\
A_{B} g \sigma_{y B}-\frac{A_{S} H}{3 D}\left[(2 H-3 g) \sigma_{u S}-(H-3 g) \sigma_{y S}\right],
\end{array}
$$

where

$$
\begin{aligned}
& H=\left(\frac{A_{D} \sigma_{u D}+2 A_{S} \sigma_{u S}-A_{B} \sigma_{y B}}{A_{S}\left(\sigma_{u S}+\sigma_{y s}\right)}\right) D \\
& g=\frac{\sigma_{y s}}{\sigma_{u s}+\sigma_{y s}} H .
\end{aligned}
$$

To calculate the ultimate moment capacity of the box using equation (2) or (3), the ultimate strength of a compressive stiffened flange and side plate members $\left(\sigma_{u D}, \sigma_{u s}\right)$ must be known. Theoretically, the idealized failure modes of a stiffened panel under compressive loads can be categorized into the following six classes (Paik, Thayamballi 2003; Hughes, Paik 2013).

- Mode I: Overall collapse of plating and stiffeners as a unit.

- Mode II: Biaxial compressive collapse without failure of the support members.

- Mode III: Beam-column type collapse.

- Mode IV: Local buckling of the stiffener web (after failure of the plating between the stiffeners).

- Mode V: Tripping of the stiffener.

- Mode VI: Gross yielding.

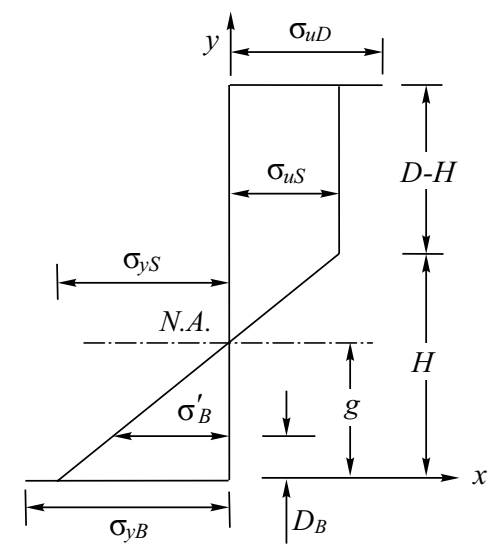

Fig. 3. Longitudinal stress distribution over the box crosssection in the overall collapse state suggested by Paik and Mansour (1995) 
The collapse of a stiffened panel can be assumed to occur at the lowest value of the ultimate load calculated from one of these six collapse patterns. As an alternative, a number of simplified formulas for predicting the ultimate compressive strength of stiffened panels are available in the literature (Paik, Thayamballi 2003), but the realistic calculation of ultimate strength that considers all possible modes and their interactions remains a relatively complicated task. In this regard, Paik and Thayamballi (1997) derived an empirical formula to predict the ultimate compressive strength of stiffened panels on the basis of data from 130 collapse tests on stiffened plates with the usual levels of initial imperfection. This formula is expressed as a function of the plate slenderness ratio $\beta$ and column (stiffener) slenderness ratio $\lambda$ (see Appendix A for further information):

$\sigma_{u} / \sigma_{y}=\left[0.995+0.936 \lambda^{2}+0.17 \beta^{2}+0.188 \lambda^{2} \beta^{2}-0.067 \lambda^{4}\right]^{-0.5}$.

Along with the ultimate strength, it is also worth calculating the section modulus of the corroded box girder over time. To achieve this, the section modulus of a single- or double-hull structure can be simply estimated as follows (Paik, Mansour 1995).

The section modulus at the outer bottom flange is

$S M=\frac{A_{D}\left(D-g^{\prime}\right)^{2}+A_{B} g^{\prime 2}+A_{B}^{\prime}\left(g^{\prime}-D_{B}\right)^{2}+A_{S} D\left(2 D-3 g^{\prime}\right) / 3}{g^{\prime}}$,

where

$g^{\prime}=\frac{D\left(A_{D}+A_{S}\right)+A_{B}^{\prime} D_{B}}{A_{D}+A_{B}+A_{B}^{\prime}+2 A_{S}}$.

For a single box girder, the formula can be simplified to

$S M=\frac{A_{D}\left(D-g^{\prime}\right)^{2}+A_{B} g^{\prime 2}+A_{S} D\left(2 D-3 g^{\prime}\right) / 3}{g^{\prime}}$,

where

$g^{\prime}=\frac{D\left(A_{D}+A_{S}\right)}{A_{D}+A_{B}+2 A_{S}}$.

In equations (5) and (6), the section modulus formula is expressed as a function of the plate thickness of the primary members, as the individual section areas are functions of the plate thickness. To calculate the mean value of the section modulus with corrosion, the reduction in the plate thickness due to corrosion is deducted from the original plate thickness.

\section{Load model}

Two types of loads apply to a bridge: dead and live loads. The fundamental statistical parameters of these loads that are most extensively used are the bias factor $\lambda$, which is the ratio of the mean to the nominal value, and the coefficient of variation $V$. The dead load includes the weight of the girders, deck slab, wearing surface, barriers, diaphragms, and sidewalk, where applicable. The values $\lambda=1.03$ and $V=0.08$ for factory-made components (girders, diaphragms), $\lambda=$ 1.05 and $V=0.10$ for cast-in-place components (deck, barriers, sidewalk), and $\lambda=1.10, V=0.25$ for asphalt wearing are applied. The dead load is treated as a normal random variable (Nowak 1993; Nowak, Szerszen 1998, 2000; Nowak, Collins 2000). The live load can be considered as the sum of the static and dynamic components. The latter can be represented by an equivalent static load that is defined as the dynamic load factor. This study employs the load model developed by AASHTO (2004) (Figure 4). The designed live load in AASHTO LRFD (2004) is specified as the effect of the design truck shown in Figure 4 superimposed with a uniformly distributed load of $9.3 \mathrm{kN} / \mathrm{m}$.

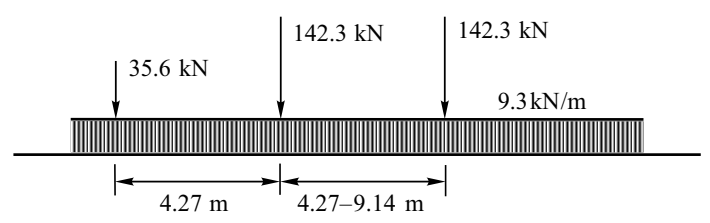

Fig. 4. Proposed nominal live loading (HL-93 live load in AASHTO LRFD, 2004)

The bias factor $\lambda$ for the live load distribution specified in the design code is between 1.10 and 1.20, and the coefficient of variation $V$ is 0.18 (Barker, Puckett 2007). A bias factor of 1.15 and a coefficient of variation of 0.18 are adopted here. The dynamic load factor (IM) is selected on the basis of the AASHTO specifications. The live load distribution for the interior and exterior girders can also be estimated using the AASHTO specifications (for further information, see ((AASHTO 2004; Barker, Puckett 2007)).

\section{Reliability analysis of corroded steel box girder bridges}

\subsection{Reliability analysis}

Structural reliability analysis can be used to calculate and predict the probability of failure (or an equivalent reliability index) of a limit state function for a structu- 
re at any time during its service life. In probabilistic assessment, any uncertainty about a variable, which is expressed in terms of its probability density function, is explicitly taken into account. Reliability analysis begins with the formulation of a limit state function that represents the performance of a structure or element in terms of several basic random variables (Paik et al. 1997, 1998; Sarveswaran, Roberts 1999). The limit state function for the steel box girders in this example is defined as follows.

$$
g(x)=M_{u}-M_{D}-M_{L} \leq 0,
$$

where $g(x)$ - the safety margin; $M_{u}$ - a random variable representing the resistance ultimate strength; $M_{D^{-}}$ a random variable representing the dead load; $M_{L}-$ a random variable representing the live load.

The aforementioned failure condition uses the limit state function for box girder collapse as a function of the three variables. However, recall that variable $M_{u}$ is actually estimated by an analytical procedure that involves the individual thicknesses, yield strength, and modulus of elasticity $\left(t, \sigma_{y}\right.$ and $\left.E\right)$ such that

$$
M_{u}=M_{u}\left(t, \sigma_{y}, E\right) .
$$

It would appear that there are five types of random variables to be characterized. In fact, however, there are six, because the thickness value of the member at any particular time is also a function of the two parameters of the corrosion rate $(A, B)$.

Reliability analysis can be performed by numerical integration, simulation, or using approximate methods such as first-order or second-order reliability methods (FORM/SORM). Numerical integration is not performed in this case because of the large dimension and the complexity of the problem. A sampling method would be time consuming because of the small probabilities involved in the analysis. The approximate methods FORM and SORM are efficient methods, and are known to provide sufficiently accurate results. Reliability analysis is thus performed using FORM. The theoretical description of this method is given in many text books (Nowak, Collins 2000; Melchers 1999; Achintya, Mahadevan 2000; Lemarie 2009).

\subsection{Typical example characteristics}

A hypothetical steel box girder bridge is employed to demonstrate the application of the proposed procedure.

The bridge has a simple span of $20.0 \mathrm{~m}$ and two lanes with traffic traveling in the same direction. The cross-section is shown in Figures 5 and 6 . The three steel box girders are made of carbon steel, and are not protected against corrosion in a marine environment. The corrosion parameters $A$ and $B$, the elasticity modulus of the steel and the steel yield stress are assumed to be lognormal variables. The mean values and standard deviations are shown in Table 2, and the coefficient of correlation between $A$ and $B$ is -0.31 . The thicknesses of the deck and asphalt are $250 \mathrm{~mm}$ and $75 \mathrm{~mm}$, respectively. The lifetime $T$ of the structure is set to 70 years.

The mean value and standard deviation of the designed dead and live loads for each girder are calculated based on the specifications provided in Section 3 . These values for the dead and live loads are treated as random variables in the limit state function developed in Section 4.1.

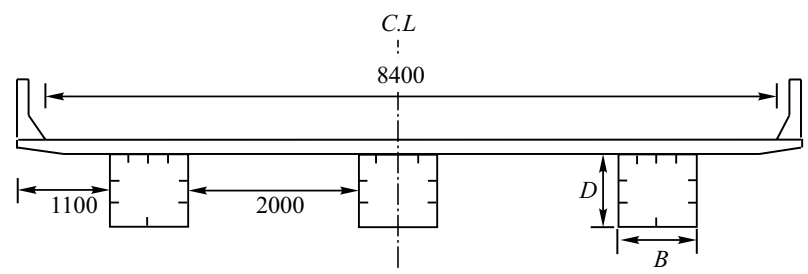

Fig. 5. Typical cross-section of a box girder bridge (dimensions in $\mathrm{mm}$ )

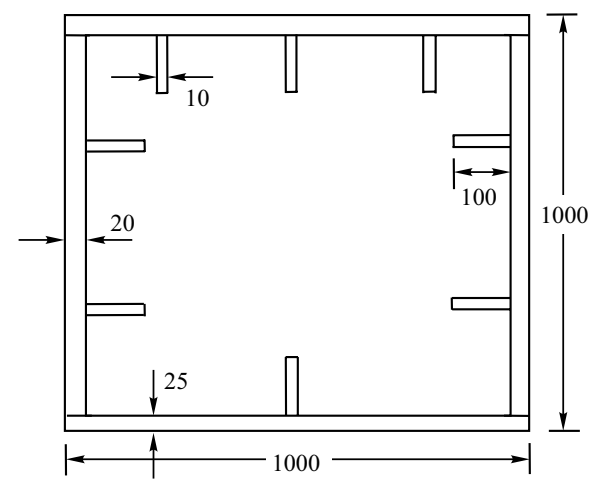

Fig. 6. Dimensions (in $\mathrm{mm}$ ) of the cross-section of the box girder

Table 2. Values used in the calculations (lognormal distributions)

\begin{tabular}{|l|c|c|}
\hline \multicolumn{1}{|c|}{ Parameters } & \multicolumn{1}{c|}{$\begin{array}{c}\text { Mean } \\
\mu\end{array}$} & $\begin{array}{c}\text { Standard deviation } \\
\sigma\end{array}$ \\
\hline $\begin{array}{l}\text { Modulus of elasticity } \\
\text { for steel, } E\end{array}$ & $2.1 \times 10^{5} \mathrm{~N} / \mathrm{mm}^{2}$ & $2.1 \times 10^{4} \mathrm{~N} / \mathrm{mm}^{2}$ \\
\hline Yield stress in steel, $\sigma_{y}$ & $350 \mathrm{~N} / \mathrm{mm}^{2}$ & $35 \mathrm{~N} / \mathrm{mm}^{2}$ \\
\hline $\begin{array}{l}\text { Corrosion parameter, } \\
A\left(A<200 \times 10^{-3} \mathrm{~mm}\right)\end{array}$ & $70.6 \times 10^{-3} \mathrm{~mm}$ & $46.6 \times 10^{-3} \mathrm{~mm}$ \\
\hline $\begin{array}{l}\text { Corrosion parameter, } \\
B(B<1.5)\end{array}$ & 0.79 & 0.39 \\
\hline
\end{tabular}




\subsection{Results and appropriate strategies for the maintenance of damaged girders}

Reliability analysis was carried out to determine the safety of existing steel box girder bridges damaged by corrosion wastage. Figures 7 and 8 show the trends of variation in reliability as the hypothetical bridge ages for the interior and exterior girders, respectively. It can be seen that the reliability of the corroded steel box is significantly reduced as the bridge ages, and that after a certain point the structural members of the girders may need repair or renewal under the assumed corrosion scenarios.

From the reliability plots, it is possible to determine a) the time at which the corroded girders must be repaired or renewed using an allowable reliability for the safety of the structure, b) the reliability degradation corresponding to the specified repair criteria, and c) the corresponding ultimate strength and section modulus for which the reliability analysis shows a risk to bridge safety before and after repair or renewal.

Valid repair or renewal criteria are developed based on the safety index degradation for box girder collapse with time. If steel repair or the renewal of corroded local members is carried out, then the reliability level of the bridge girder increases immediately after repair, although the trend of decreasing reliability with age continues. Hence, a large jump in the reliability index is observed after local member renewal or repair due to corrosion degradation.

To determine the repair time, allowable reliability (Target) is needed. The target reliability can be different for primary and secondary components and simple load path and multiple load path components, and further depends on the time interval between inspections (Nowak 2004). In this study, the target reliability is set to 3.5 (Nowak, Szerszen 2000). This makes the earliest repair time for corroded steel box girders around nine and eight years for the interior and exterior girders, respectively (Figures 7,8 ). Once the age at which girder safety may be at risk (less than the target value) has been reached, the girder must be repaired or renewed. There are various strategies for the repair or renewal of corrosion-damaged steel box girders, but the simplest and optimal method applicable should always be selected. The usual manner of repair is to install additional plates with different thicknesses on the surface of plate members with decreased thicknesses due to corrosion damage. Here, only the bottom plate is repaired at each instance of repair.
As it is only necessary to restore the bottom plate to its primary thickness at each intervention, the side plates and stiffeners are not repaired, and will thus become thinner as the bridge ages. This means that the ultimate steel box strength will be less than its earlier strength. This trend can be seen in Figures 9 and 10 for the interior and exterior girders, respectively, where the maximum ultimate flexural resistance bending decreases as the bridge ages.

Although the ultimate moment strength after each repair is less than that at the bridge's earlier repair state (because it is assumed that only the bottom flange has been restore to the primary thickness and the side plates and stiffeners will be corroded, and thus the ultimate moment of the box will be less than in its earlier state), the reliability index is more than the target value as the bridge ages (Figures 7 and 8 ). The maximum reliability values after each repair interven-

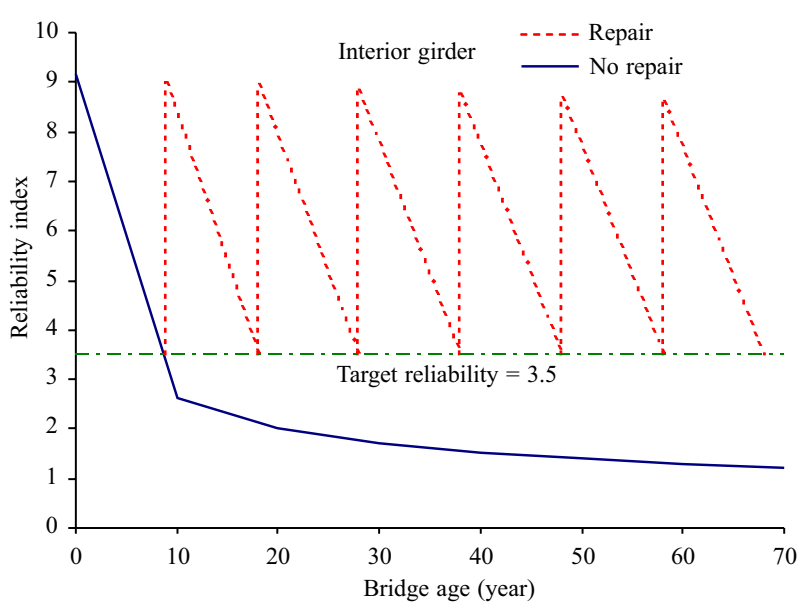

Fig. 7. Variation in the reliability of the interior girder of the bridge with age

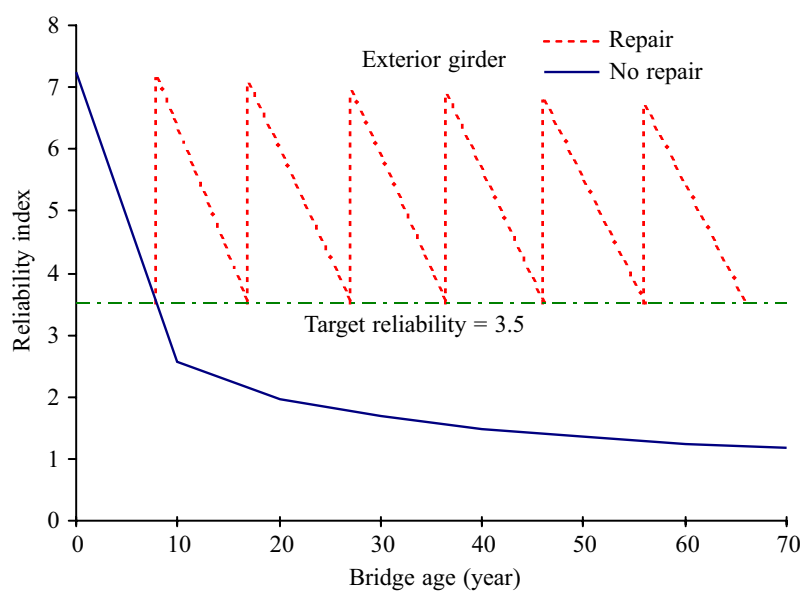

Fig. 8. Variation in the reliability of the exterior girder of the bridge with age 
tion decrease as bridge ages, and a similar trend is observed for the ultimate moment strength and section modulus as shown in Figures 9-12. Figures 9-12 show that, unlike the maximum reliability indices and section modulus, the reduction in the maximum ultimate moment strength after each repair intervention is remarkable. This trend can be attributed to the type of repair assumed. As noted, although the thickness of the bottom flange plate is restored to the primary thickness at each repair intervention, the thicknesses of the stiffeners and side plates continue to decrease, and thus the ultimate strength also decreases.

\section{Concluding remarks}

The aim of the study reported here was to develop and illustrate some important aspects of a reasonably accurate procedure for assessing the ultimate strength reliability level of corroded steel box girder

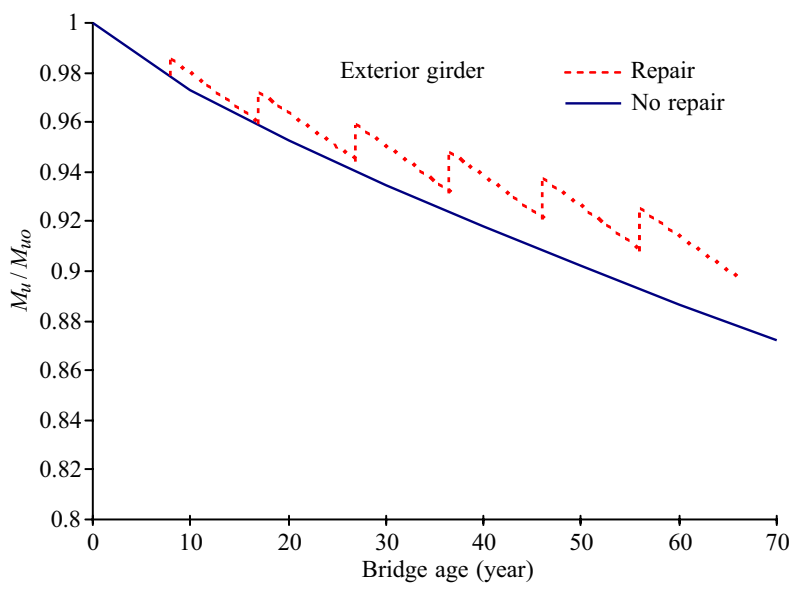

Fig. 9. Variation in the ultimate moment of the interior girder of the bridge with age

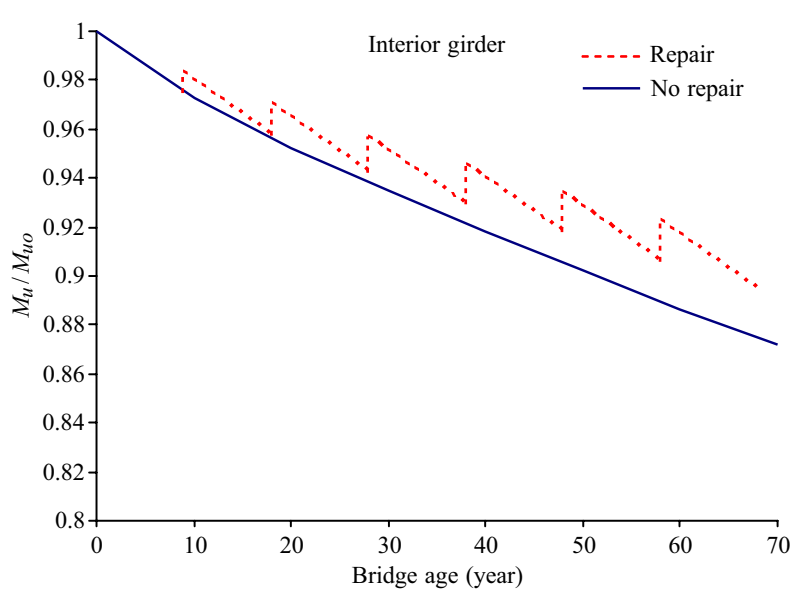

Fig. 10. Variation in the ultimate moment of the exterior girder of the bridge with age bridges. A corrosion scenario for the cross-section of stiffened steel box girders is developed based on available statistical data on the corrosion rate for existing bridges, and a model of a corrosion-damaged girder cross-section is established. The probabilistic ultimate box strength model is based on the simple analytical formulation derived by Paik and Mansour (1995) and formulated based on the AASHTO specifications. The reliability level of the box girder is calculated by using the first-order reliability method (FORM). As an illustrative example, the procedure is applied to a hypothetical corroded steel box girder bridge, and various potential applications of the method, such as in the determination of inspection planning and renewal criteria are discussed. The following conclusions can be drawn.

1) The section modulus and ultimate strength of corroded box girders decrease with time, but

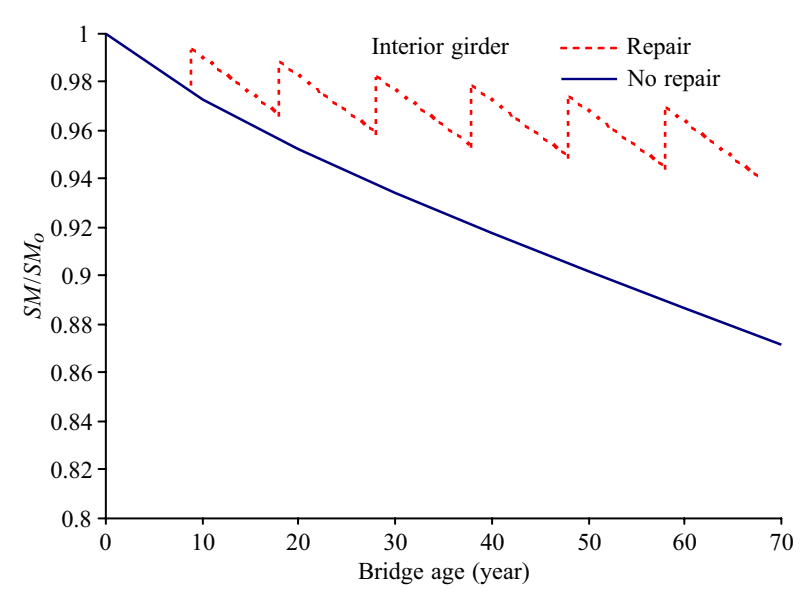

Fig. 11. Variation in the section modulus of the interior girder of the bridge with age

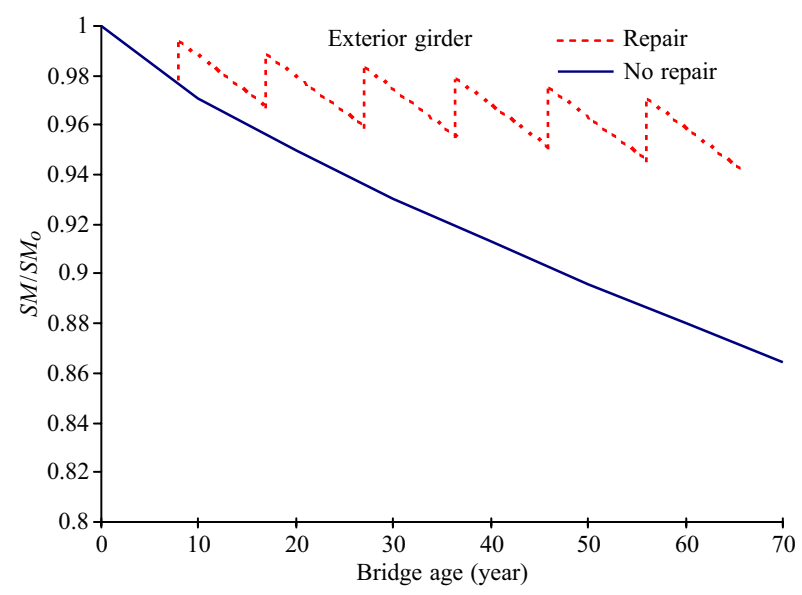

Fig. 12. Variation in the section modulus of the exterior girder of the bridge with age 
the degree of change can be controlled through the appropriate application of technology, inspections and steel repair or renewal criteria.

2) Through the appropriate repair or renewal of corroded local members, the ultimate strength reliability of the box girder increases immediately after repair, although the repair intervention does cause a small decrease in ultimate strength.

3) The developed procedure may be useful for assessing the ultimate strength reliability of aging bridges, taking into account the degradation of the primary member plates due to corrosion. The procedure can be applied to establish effective maintenance strategies and minimize the cost of bridge maintenance for specific cases involving corrosion.

4) Analysis based on reliability can be useful to keep a steel box girder bridge within the necessary safety margin through optimized and appropriate intervention. The proposed procedure can be employed by practicing engineers responsible for the maintenance and repair of corrosion-damaged steel box girder bridges.

\section{Acknowledgements}

The work reported herein was undertaken at the Lloyd's Register Foundation Research Centre of Excellence at Pusan National University. Lloyd's Register Foundation (LRF), a UK registered charity and sole shareholder of Lloyd's Register Group Ltd, invests in science, engineering and technology for public benefit, worldwide. This research was supported by Leading Foreign Research Institute Recruitment Program through the National Research Foundation of Korea(NRF) funded by the Ministry of Science, Ict \& future Planning(MSIP) (Grant no.: 2013044761).

\section{References}

AASHTO. 2004. AASHTO LRFD. Bridge design specifications, American Association of State Highway and Transportation Officials. Washington, D.C.

Achintya, H.; Mahadevan, S. 2000. Probability, reliability and statistical methods in engineering design. Hoboken, New Jersey, USA: John Wiley \& Sons, Inc.

Barker, R. M.; Puckett, J. A. 2007. Design of highway bridges and LRFD approach. Hoboken, New Jersey, USA: John Wiley \& Sons, Inc.

Czarnecki, A. A.; Nowak, A. S. 2008. Time-variant reliability profiles for steel girder bridges, Structural Safety 30: 49-64. http://dx.doi.org/10.1016/j.strusafe.2006.05.002
Gayton, N.; Lemaire, M. 2009. Reliability assessment of structures subjected to fatigue failure, Ships and Offshore Structures 4(3): 229-239. http://dx.doi.org/10.1080/17445300903102896

Gordo, J. M.; Guedes Soares, C. 2009. Experimental evaluation of the behaviour of a mild steel box girder under bending moment, Ships and Offshore Structures 3(4): 347-358. http://dx.doi.org/10.1080/17445300802370479

Hughes, O. F.; Paik, J. K. 2013. Ship structural analysis and design. The Society of Naval Architects and Marine Engineers, Wasington DC, USA.

Ivanov, L. D. Reliability estimation of ship's hull girder in probabilistic terms when ultimate strength is used as a failure mode, Ships and Offshore Structures 8(2): 141-153. http://dx.doi.org/10.1080/17445302.2012.664400

Kayser, J. R. 1988. The effects of corrosion on the reliability of steel girder bridges: $\mathrm{PhD}$ thesis. University of Michigan, Ann Arbor, Mich., USA.

Kayser, J. R.; Nowak, A. S. 1989. Reliability of corroded steel girder bridges, Structural Safety 6: 53-63. http://dx.doi.org/10.1016/0167-4730(89)90007-6

Komp, M. E. 1987. Atmospheric corrosion ratings of weathering steels - calculation and significance, Materials Performance 26: $42-44$.

Lazakis, I.; Turan, O.; Aksu, S. 2010. Increasing ship operational reliability through the implementation of a holistic maintenance management strategy, Ships and Offshore Structures 5(5): 337-357. http://dx.doi.org/10.1080/17445302.2010.480899

Lemarie, M. 2009. Structural reliability. Hoboken, New Jersey, USA: John Wiley \& Sons, Inc. http://dx.doi.org/10.1002/9780470611708

Melchers, R. E. 1999. Structural reliability analysis and prediction. Chichester, UK: Wiley.

Melchers, R. E. 2005. The effect of corrosion on the structural reliability of steel offshore structures, Corrosion Science 47(10): 2391-2410. http://dx.doi.org/10.1016/j.corsci.2005.04.004

Melchers, R. E.; Jeffrey, R. J. 2008. Probabilistic models for steel corrosion loss and pitting of marine infrastructure, Reliability Engineering and System Safety 93: 423-432. http://dx.doi.org/10.1016/j.ress.2006.12.006

Nowak, A. S. 1993. Live load model for highway bridges, Structural Safety 13: 53-66. http://dx.doi.org/10.1016/0167-4730(93)90048-6

Nowak, A. S. 2004. System reliability models for bridge structures, Bulletin of the Polish Academy of Sciences: Technical Sciences 52(4): 321-328.

Nowak, A. S.; Collins, K. R. 2000. Reliability of structures. Boston, USA: Thomas Casson, McGraw-Hill.

Nowak, A. S.; Szerszen, M. M. 1998. Bridge load and resistance models, Engineering Structures 20(11): 985-990. http://dx.doi.org/10.1016/S0141-0296(97)00193-4

Nowak, A. S.; Szerszen, M. M. 2000. Structural reliability as applied to highway bridges, Progress in Structural Engineering and Materials 2: 218-224. http://dx.doi.org/10.1002/1528-2716(200004/06)2:2<218:: AID-PSE27>3.0.CO;2-8

Nowak, A. S.; Zhou, J. 1990. System reliability models for bridges, Structural Safety 7: 247-254. http://dx.doi.org/10.1016/0167-4730(90)90073-X 
Paik, J. K.; Kim, D. K.; Park, D. H.; Kim, H. B.; Mansour, A. E.; Caldwell, J. B. 2013. Modified Paik-Mansour formula for ultimate strength calculations of ship hulls, Ships and Offshore Structures 8(3-4): 245-260.

http://dx.doi.org/10.1080/17445302.2012.676247

Paik, J. K.; Kim, S. K.; Lee, S. K. 1998. Probabilistic corrosion rate estimation model for longitudinal strength members of bulk carriers, Ocean Engineering 25: 837-860. http://dx.doi.org/10.1016/S0029-8018(97)10009-9

Paik, J. K.; Kim, S. K.; Yang, S. H.; Thayamballi, A. K. 1997. Ultimate strength reliability of corroded ship hulls, Royal Institution of Naval Architects 140: 1-18.

Paik, J. K.; Mansour, A. E. 1995. A simple formulation for predicting the ultimate strength of ships, Journal of Marine Science and Technology 1: 52-62.

http://dx.doi.org/10.1007/BF01240013

Paik, J. K.; Melchers, R. E. 2008. Condition assessment of aged structures. New York, USA: CRC Press. http://dx.doi.org/10.1533/9781845695217

Paik, J. K.; Thayamballi, A. K. 1997. An empirical formulation for predicting the ultimate compressive strength of stiffened panels, in Proc. $7^{\text {th }}$ International Offshore and Polar Engineering Conference, 25-30 May 1997, Honolulu, USA, vol. IV, 328-338.

Paik, J. K.; Thayamballi, A. K. 2003. Ultimate limit state design of steel-plated structures. Hoboken, New Jersey, USA: John Wiley \& Sons, Ltd.

Paik, J. K.; Thayamballi, A. K.; Kim, S. K.; Yang, S. H. 1998. Ship hull ultimate strength reliability considering corrosion, Journal of Ship Research 42: 154-165.

Payer, H. G.; Schellin, T. E. A class society's view on rationally based ship structural design, Ships and Offshore Structures 8(3-4): 319-336.

http://dx.doi.org/10.1080/17445302.2012.747465
Reid, S. G. 2009. Calculation and interpretation of realistic reliability estimates, Ships and Offshore Structures 4(3): 197-205. http://dx.doi.org/10.1080/17445300903102888

Saad-Eldeen, S.; Garbatov, Y.; Guedes Soares, C. 2013. Experimental assessment of corroded steel box-girders subjected to uniform bending, Ships and Offshore Structures 8(6): 653-662. http://dx.doi.org/10.1080/17445302.2012.7181

Sarveswaran, V.; Roberts, M. B. 1999. Reliability analysis of deteriorating structures - the experience and needs of practicing engineers, Structural Safety (21): 357-372. http://dx.doi.org/10.1016/S0167-4730(99)00030-2

Sharifi, Y. 2011. Reliability of deteriorating steel box-girder bridges under pitting corrosion, Advanced Steel Construction 7(3): 220-238.

Sharifi, Y.; Paik, J. K. 2011. Ultimate strength reliability analysis of corroded steel-box girder bridges, Thin-Walled Structures 49(1): 157-166. http://dx.doi.org/10.1016/j.tws.2010.09.001

Sharifi, Y.; Paik, J. K. 2010. Environmental effects on ultimate strength reliability of corroded steel box girder bridges, Structural Longevity 18(1): 1-20.

Sharifi, Y.; Tohidi, S. 2014a. Lateral-torsional buckling capacity assessment of web opening steel girders by artificial neural networks-elastic investigation, Frontiers of Structural and Civil Engineering 8(2): 167-177. http://dx.doi.org/10.1007/s11709-014-0236-Z

Sharifi, Y.; Tohidi, S. 2014b. Ultimate capacity assessment of web plate beams with pitting corrosion subjected to patch loading by artificial neural networks, Advanced Steel Construction 10(3): 325-350.

Tohidi, S.; Sharifi, Y. 2014. Restrained distortional buckling capacity of half-through bridge girders, The IES Journal Part A: Civil \& Structural Engineering 7(3): 163-173. http://dx.doi.org/10.1080/19373260.2014.955139

\section{Appendix A}

\section{Calculation of the ultimate compressive strength of a stiffened panel}

The ultimate compressive strength of a stiffened panel can be estimated using the empirical formula in equation (4). Figure A shows a longitudinal stiffener section taken from a stiffened panel, where the length between the transverse beams is $l$, the spacing between the longitudinal stiffeners is $b$, the yield strength of the material is $\sigma_{y}$ and the Young's modulus is $E$. The parameters used in equation (4) are defined as follows.

a)

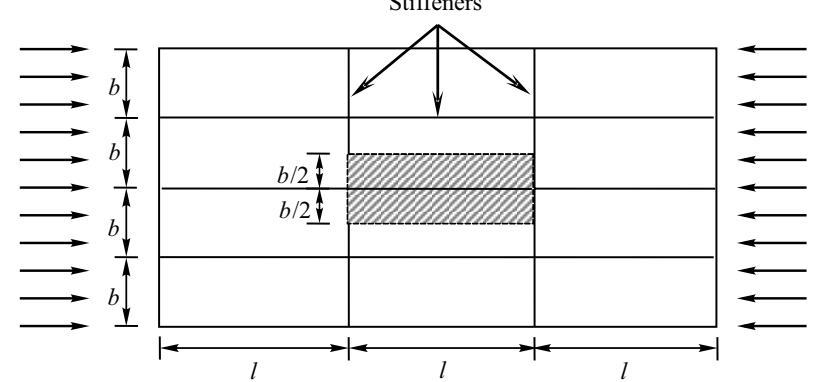

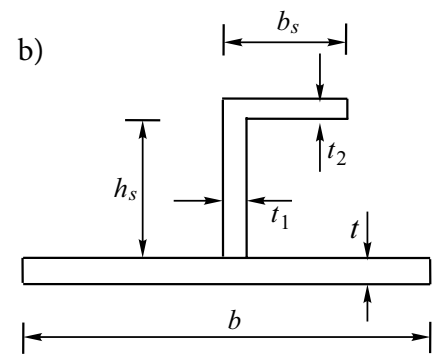

Fig. A. Stiffener cross-section: (a) Stiffened panel; (b) Longitudinal stiffener section with effective plating (Paik, Thayamballi 1997) 
(a) Mean yield strength $\sigma_{y}$ of the whole stiffened panel (when the material property of the stiffener differs from that of the plate)

$$
\sigma_{y}=\frac{\sigma_{y p}+\xi \sigma_{y s}}{1+\xi}
$$

where

$\xi=\frac{h_{s} t_{1}+b_{s} t_{2}}{b t}$,

$\sigma_{y p}, \sigma_{y s}=$ the yield strength of the plating or stiffener.

(b) Sectional area $a_{s}$ :

$a_{s}=b t+h_{s} t_{1}+b_{s} t_{2}$.

(c) Height of the neutral axis from the base line of the plate $Z_{0}$ :

$$
Z_{0}=\frac{\frac{b t^{2}}{2}+h_{s} t_{1}\left(t+\frac{h_{s}}{2}\right)+b_{s} t_{2}\left(t+h_{s}+\frac{t_{2}}{2}\right)}{a_{s}} .
$$

(d) Moment of inertia $I_{s}$ :of one stiffener with fully effective plating

$$
I_{s}=\frac{b t^{3}}{12}+b t\left(Z_{0}-\frac{t}{2}\right)^{2}+\frac{h_{s}^{3} t_{1}}{12}+h_{s} t_{1}\left(Z_{0}-t-\frac{h_{s}}{2}\right)^{2}+\frac{b_{s} t_{2}^{3}}{12}+b_{s} t_{2}\left(Z_{0}-t-h_{s}-\frac{t_{2}}{2}\right)^{2} .
$$

(e) Radius of gyration $r$ of one stiffener with fully effective plating

$$
r=\sqrt{\frac{I_{s}}{a_{s}}}
$$

(f) Plate slenderness ratio $\beta$ :

$$
\beta=\frac{b}{t} \sqrt{\frac{\sigma_{y}}{E}} .
$$

(g) Column (stiffener) slenderness ratio $\lambda$ :

$$
\lambda=\frac{l}{\pi r} \sqrt{\frac{\sigma_{y}}{E}} .
$$

(h) Ultimate compressive strength $\sigma_{u}$ :

$$
\sigma_{u} / \sigma_{y}=\left(0.995+0.936 \lambda^{2}+0.170 \beta^{2}+0.188 \lambda^{2} \beta^{2}-0.067 \lambda^{4}\right)^{-0.5}
$$

Yasser SHARIFI is an Associate Professor of the structural engineering at Vali-e-Asr University of Rafsanjan in Iran. His areas of research are buckling and ultimate capacities of structures in association with limit states and risk-based approaches, and the other his research has been ranging from large scale (complete buildings) to small scale (material level) within the field of concrete structures.

Jeom Kee PAIK is a professor of the Department of Naval Architecture and Ocean Engineering at Pusan National University in Busan, Korea. He serves as president of the Korea Ship and Offshore Research Institute and also as director of the Lloyd's Register Foundation Research Centre of Excellence at the University. He is a fellow and council member of The Royal Institution of Naval Architects in UK, and a fellow and vice president of The Society of Naval Architects and Marine Engineers, USA. 